\title{
X-linked myopathy with postural muscle atrophy
}

INSERM

\section{Source}

INSERM. (1999). Orphanet: an online rare disease and orphan drug data base. X-linked myopathy with postural muscle atrophy. ORPHA:178461

X-linked myopathy with postural muscle atrophy is a rare progressive muscular dystrophy characterized by an adult-onset scapulo-axio-peroneal myopathy. Clinical presentation includes shoulder girdle atrophy, scapular winging, axial muscular atrophy of postural muscles combined with a generalized hypertrophy. Typically, neck rigidity, rigid spine, Achilles tendon shortening, and respiratory insufficiency later in disease course are present. 